\title{
ASSESSMENT OF VALUE FOR CULTIVATION AND USE (VCU) TRIAL DATA BY GGE-BIPLOT ANALYSIS IN BREAD WHEAT (TRITICUM AESTIVUM L.)
}

\author{
AKTAS, B. \\ Variety Registration and Seed Certification Center, Ankara, Turkey \\ (e-mail: bekir_aktas@yahoo.com; phone: +90-538-433-6374; fax: +90-312-315-0901) \\ (Received 21 $1^{\text {st }}$ May 2019; accepted $10^{\text {th }}$ Sep 2019)
}

\begin{abstract}
The study was carried out with 17 bread wheat (Triticum aestivum L.) genotypes in 7 different environments under rain-fed conditions of the Thrace region in Turkey during 2014-2015 and 2015-2016 growing seasons. Value for cultivation and use (VCU) trial data on yield and quality traits (1000-kernel weight, test weight, protein content, Zeleny sedimentation and alveograph energy value) of bread wheat genotypes were assessed through GGE-biplot analysis. Variance analysis revealed significant genotype $(\mathrm{G}) \times$ environment (E) interaction (GEI). GGE-biplot analysis explained $79.18 \%$ of total variation. Environment-focused assessments revealed 3 mega-environments (ME). E7 (Luleburgaz-2016) was identified as the best representative of all environments and had the greatest separation power among the genotypes. According to the average environment coordinate (AEC), of the genotypes with high PC1 (Principal component) scores, the ones with a PC2 score close to 0.0 were identified as the most stable genotypes. G15, G14, G10 and G13 were the closest genotypes to AEC apsis and they had high PC1 scores. Biplot graphs were generated for 5 quality traits and stabilities of genotypes were put forth based on their positions with respect to AEC. In VCU trials, 5 control cultivars were also used and the average of control cultivars (AC) was generated. AC-focused comparisons of the genotypes were performed. It was concluded based on the present findings that GGE-biplot analysis facilitated the assessments of VCU trial data on yield and quality traits.
\end{abstract}

Keywords: genotype $\times$ environment interaction, grain yield, quality, stability, multi-environment trials

\section{Introduction}

Wheat is among the leading agricultural products of Turkey with optimal available ecological conditions for its culture. Since the country is composed of different agroecological zones, breeders are directed to select appropriate genotypes for these zones or regions. Therefore, variety registration trials for wheat are conducted regionally. In the variety breeding efforts, selection criteria vary based on climate, soil, diseases and pests of the region. In other words, varieties developed by breeders in accordance with their regional adaptation capacities are tested in official registration trials.

In VCU trials, Thrace and Southern Marmara constituting the Marmara region are taken into consideration under different categories due to the different environmental conditions of these two zones. The Thrace region has the second greatest annual precipitation after the Black Sea region according to long-term climate data (TSMS, 2018).

In VCU trials, candidate varieties are compared to control cultivars. The registration committee assesses the candidate varieties for yield, quality, resistance to diseases and economic value and then the ones equivalent to or better than the control cultivars are registered (RTMAF, 2008). Widely cultivated and accepted varieties by both the farmers and the industry are used as the control varieties in VCU trials. The VCU trials are conducted during at least two growing seasons and in at least 3 locations in each growing season. The varieties are grouped according to their performance using several statistical analyses. However, genotypes may have different responses to varying 
environmental conditions. Genotype by environment interaction (GEI) is a phenotypic outcome of interaction between genotype and environment (Gebru et al., 2011). The phenotypic effects manifest themselves in yield, quality, diseases or the other attributes. Plant breeders consider phenotypic characteristics of the genotypes in different environments while selecting genotypes under the existence of GEI. In VCU trials, variety register experts assess the performance of candidate varieties in different environments. Although regional adaptation is taken into consideration in wheat VCU trials of Turkey, each region is divided into sub-regions or zones with different ecologies.

The significance of GEI is attempted to be revealed through variance analysis and different statistical parameters have been developed to elucidate response of genotypes to different environmental conditions. In the present study, GGE-Biplot method developed by Gabriel (1971) to assess G and GEI in multi-environment and multigenotype trials was used. Biplot analysis facilitates a visual presentation of data. The method separates environments into mega environments based on genotype performances and points out which genotype is better in which environment (Yan et al., 2000). Biplot analysis also allows the user to compare the genotypes and environments and to estimate ideal genotypes for each environment, thus facilitate the assessment of VCU trials. For bread wheat, previous researchers used biplot analysis to assess yield (Kaya et al., 2006; Tulu and Wondimu, 2019), quality (Aktas et al., 2017) and disease data (Akcura et al., 2017). Xu et al. (2017) pointed out the significance of superior cultivars in cultivar registration system and indicated that quality should also be taken into consideration besides the yield levels in cotton. Researchers convert environment into a trait in GGE-biplot analysis and assessed candidate cultivars through GT-Biplot (Genotype by trait) by scaling all traits. GGE-Biplot analysis was used to assess cotton genotypes (Farias et al., 2016), maize genotypes (Oyekunle et al., 2017), barley genotypes (Solonechnyi et al., 2015) and potato genotypes (Flis et al., 2014).

The supports provided for certified seeds have brought about significant developments in the seed industry of Turkey. The number of varieties brought from abroad and applied for registration increased significantly. The majority of these varieties are Europe-originated ones and applied for registration in irrigated or rain-fed conditions of Thrace and Central Anatolia regions. It is quite significant to test candidate varieties together with control cultivars in different environments and to assess the trial outcomes together. Recent climate extremities increased the significance of variety stability. Put forth of response of candidate varieties to poor and ideal environmental conditions through VCU trials will facilitate the decision of the registration committee.

This study was conducted with 17 bread wheat genotypes at 7 different environments under rain-fed conditions of Thrace region in 2014-2015 and 2015-2016 growing seasons to assess genotype-environment interactions for grain yield and some quality traits through variety registration trials.

\section{Materials and methods}

Present experiments were conducted with 17 bread wheat genotypes at 7 different environments of the Thrace region in 2014-2015 and 2015-2016 growing seasons in randomized blocks design with 4 replications. Growing seasons and locations are provided in Table 1 and locations are also shown on the map (Fig. 1). 12 bread wheat 
genotypes (Energo, Yigit, Maya, Asli, Huseyinbey, Dunaviya, Pannonia, Misiia Odes'ka, Rebelde, Nomade, Os Jelena and Duru 17) and 5 control cultivars (Gelibolu, Kate A-1, Selimiye, Pehlivan, Krasunia odes'ka) were the plant material of the study. Experiments were set up on $9 \mathrm{~m}$ long plots with 6 rows in each plot spaced $17.0 \mathrm{~cm}$ apart. Sowing was performed with a 6-row grain drill as to have 500 seeds per $\mathrm{m}^{2}$ arranged based on thousand-seed weight of the varieties. To each plot, $200 \mathrm{~kg} \mathrm{ha}^{-1}$ composed fertilizer (20-20-0) was applied at sowing, $150 \mathrm{~kg} \mathrm{ha}^{-1}$ urea (46\%) was applied in February and $180 \mathrm{~kg} \mathrm{ha}^{-1}$ ammonium nitrate (26\%) was applied in April. Harvest was performed in the last week of June with a plot combine harvester. Side effects were omitted from the plots and harvest area $8 \mathrm{~m}^{2}$ was used in assessments.

Table 1. Genotypes and experimental locations

\begin{tabular}{c|c|c|c|c|c}
\hline Code & Genotype & Origin of genotype & Code & Growing season & Location \\
\hline G1* & Gelibolu & Edirne-Turkey & E1 & $2014-2015$ & Kesan \\
G2* & Kate A-1 & Bulgaria & E2 & $2015-2016$ & Kesan \\
G3* & Selimiye & Edirne-Turkey & E3 & $2014-2015$ & Edirne \\
G4* & Pehlivan & Edirne-Turkey & E4 & $2015-2016$ & Edirne \\
G5* & Krasunia odes'ka & Ukraine & E5 & $2014-2015$ & Tekirdag \\
G6 & Energo & Austria & E6 & $2015-2016$ & Tekirdag \\
G7 & Yigit & Kesan-Turkey & E7 & $2015-2016$ & Luleburgaz \\
G8 & Maya & Tekirdag-Turkey & & & \\
G9 & Asli & Austria & & & \\
G10 & Huseyinbey & Tekirdag-Turkey & & & \\
G11 & Dunaviya & Bulgaria & & & \\
G12 & Pannonia & Serbia & & & \\
G13 & Misiia Odes'ka & Ukraine & & & \\
G14 & Rebelde & Italy & & & \\
G15 & Nomade & Italy & & & \\
G16 & Os Jelena & Croatia & & & \\
G17 & Duru 17 & Croatia & & & \\
\hline
\end{tabular}

*Control cultivars

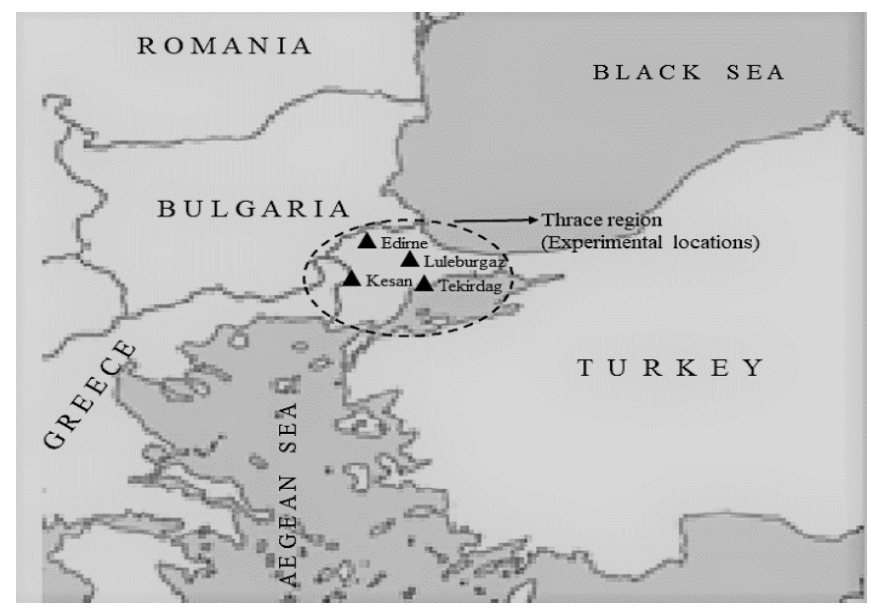

Figure 1. The view of experimental locations on the map 
Quality criteria such as 1000-kernel weight, test weight, protein content, Zeleny sedimentation and alveograph energy values were determined. For 1000-kernel weight, $4 \times 100$ kernels were randomly selected. They were then weighed to calculate 1000kernel weight. Results were expressed in dry matter. Hectoliter or test weight was determined in accordance with Uluoz (1965). Protein content was determined in accordance with ICC 105/2 method and results were expressed in dry matter (ICC, 2002a). Zeleny sedimentation analysis was performed in accordance with ICC 116-1 method (ICC, 2002b) and alveograph analysis was performed in accordance with AACC 54.50 (AACC, 2000).

Monthly precipitation and average temperatures of the experimental locations for growing seasons are provided in Table 2. In the first growing season, total precipitations were greater than the long-term averages in Edirne, Luleburgaz and Tekirdag locations and lower than long-term averages in Kesan location. In the second growing season, all locations, except for Edirne, had total precipitations lower than the long-term averages. With regard to total monthly precipitations, deviations were observed from the longterm averages in both experimental years. In general, monthly average temperatures were greater than the long-term averages in all locations. Especially in the second growing season, average temperatures were quite greater than both the first growing season and the long-term averages.

Since the locations were not same to each growing season, statistical analyses for yield and quality parameters were performed through assuming each location as an environment. For grain yield, a combined variance analysis over the environments was performed. The GGE biplot method was used to identify genotype-environment interactions for yield and quality parameters. GenStat (Genstat, 2009) statistical analysis software was used for GGE-Biplot analysis.

\section{Results and discussion}

\section{Grain yield}

Results of combined variance analysis over the environments for grain yields are provided in Table 3. According to variance analysis, G, E and GEI were found to be significant $(\mathrm{p}<0.01)$. The coefficient of variation was calculated as $8.96 \%$.

The mean yields of bread wheat genotypes over 7 environments are given in Table 4 . The highest yield was obtained from E1 (Kesan-2015) environment and the lowest yield was obtained from E4 (Edirne-2016) environment. Considering the results obtained from all environments, the genotype G15 (Nomade) had the greatest grain yield. G14, G10, G9 and G13 were in the same statistical group with G15. With regard to grain yield of G15 in different environments, it gave the highest yields in E4, E6 and E7 environments. However, for grain yield performance, G15 was ranked as $14^{\text {th }}$ in E1 and $13^{\text {th }}$ in E3 environment. Considering the grain yields of the other genotypes, they exhibited more or less different performances in different environments.

GGE-biplot analysis was able to explain $79.18 \%$ of GGE-induced variation in the grain yields of 17 bread wheat genotypes tested at 7 different environments. In the environment-focused model, GGE ratio was $62.50 \%$ over PC1 axis and $16.68 \%$ over PC2 axis. Also, in the environment-focused GGE-biplot graph, all of the environments had positive PC1 values and such a case indicate the existence of non-crossover GEI (Fig. 2). For PC2, environments had either negative or positive values. With regard to PC2, environments indicated the existence of crossover GEI. The vector lengths from 
the biplot origin and the angles between the vectors of the environments were different. Vector lengths of the environments indicate the separation power among the genotypes (Yan and Kang, 2003). The angles between the vectors reveal significant information for comparison of the environments. Lower angles between the vectors indicate increasing similarity between the environments and closer response of genotypes in those environments (Yan, 2001). Obtuse angle between E1 (Kesan-2015) and E5 (Tekirdag-2015) vectors indicate that the performance of environments or genotypes was not similar. On the other hand, acute angles between E2, E3, E4, E6 and E7 vectors indicated that these environments were placed in the same mega-environment (Fig. 3). E1 and E5 constituted the other 2 mega-environments.

Table 2. Monthly precipitation $(\mathrm{mm})$ and average temperature $\left({ }^{\circ} \mathrm{C}\right)$ data for the experimental years and locations

\begin{tabular}{|c|c|c|c|c|c|c|c|c|c|c|c|c|}
\hline \multirow[b]{3}{*}{ Months } & \multicolumn{12}{|c|}{ Precipitation (mm) } \\
\hline & \multicolumn{3}{|c|}{ Edirne } & \multicolumn{3}{|c|}{ Tekirdag } & \multicolumn{3}{|c|}{ Kesan } & \multicolumn{3}{|c|}{ Luleburgaz* } \\
\hline & $\mathbf{A}$ & $\mathbf{B}$ & $\mathbf{C}$ & $\mathbf{A}$ & B & $\mathbf{C}$ & $\mathbf{A}$ & B & $\mathbf{C}$ & $\mathbf{A}$ & B & $\mathbf{C}$ \\
\hline September & 105.0 & 29.5 & 37.2 & 92.2 & 34.9 & 33.6 & 121.4 & 63.0 & 34.0 & 4.8 & 35.0 & 34.2 \\
\hline October & 121.8 & 52.6 & 57.7 & 131.0 & 83.7 & 62.4 & 59.2 & 97.2 & 58.0 & 89.9 & 80.4 & 54.4 \\
\hline November & 43.2 & 26.2 & 68.1 & 35.2 & 48.5 & 75.4 & 22.4 & 26.2 & 84.0 & 64.6 & 31.9 & 66.1 \\
\hline December & 111.3 & 0.3 & 70.0 & 80.3 & 0.6 & 81.5 & 93.4 & 3.0 & 102.0 & 116.3 & 0 & 70.6 \\
\hline January & 42.2 & 114.8 & 66.7 & 49.4 & 70.7 & 68.8 & 56.4 & 85.0 & 81.0 & 98.7 & 97.2 & 61.9 \\
\hline February & 68.6 & 89.2 & 52.0 & 90.3 & 68.4 & 54.1 & 58.8 & 77.0 & 72.0 & 36.1 & 91.4 & 51.0 \\
\hline March & 67.8 & 54.8 & 51.6 & 29.4 & 30.6 & 54.4 & 59.8 & 23.6 & 69.0 & 43.5 & 20.9 & 46.6 \\
\hline April & 44.4 & 116.1 & 47.2 & 60.1 & 22.9 & & 69.8 & 28.8 & 51.0 & 67.1 & 46.0 & 45.6 \\
\hline May & 45.2 & 81.4 & 53.3 & 32.0 & 28.4 & 36.7 & 9.0 & 45.4 & 40.0 & 24.2 & 50.6 & 49.4 \\
\hline June & 31.0 & 10.2 & 46.5 & 58.4 & 35.0 & 37.9 & 42.8 & 40.4 & 36.0 & 67.9 & 26.2 & 47.4 \\
\hline \multirow[t]{3}{*}{ Total } & 680.5 & 575.1 & 550.3 & 658.3 & 423.7 & 545.7 & 593.0 & 489.6 & 627.0 & 613.1 & 479.6 & 527.2 \\
\hline & \multicolumn{12}{|c|}{ Average temperature $\left({ }^{\circ} \mathrm{C}\right)$} \\
\hline & \multicolumn{3}{|c|}{ Edirne } & \multicolumn{3}{|c|}{ Tekirdag } & \multicolumn{3}{|c|}{ Kesan } & \multicolumn{3}{|c|}{ Luleburgaz* } \\
\hline Months & $\mathbf{A}$ & B & $\mathbf{C}$ & $\mathbf{A}$ & B & $\mathbf{C}$ & $\mathbf{A}$ & B & $\mathbf{C}$ & $\mathbf{A}$ & B & $\mathbf{C}$ \\
\hline September & 20.9 & 24.0 & 19.9 & 20.7 & 22.7 & 20.0 & 18.9 & 24.8 & 19.6 & 18.6 & 22.1 & 19.3 \\
\hline October & 15.4 & 15.6 & 14.2 & 15.6 & 16.5 & 15.4 & 13.8 & 14.1 & 14.4 & 13.1 & 14.7 & 13.9 \\
\hline November & 9.3 & 13.5 & 9.1 & 11.2 & 13.8 & 11.0 & 9.7 & 22.8 & 9.9 & 8.0 & 12.7 & 9.1 \\
\hline December & 6.6 & 5.5 & 4.6 & 9.3 & 7.3 & 7.1 & 7.3 & 4.8 & 6.0 & 6.8 & 5.5 & 5.0 \\
\hline January & 3.8 & 2.8 & 2.7 & 5.8 & 5.6 & 4.7 & 5.1 & 3.7 & 3.7 & 4.0 & 3.5 & 2.9 \\
\hline February & 6.4 & 9.8 & 4.5 & 6.5 & 9.6 & 5.4 & 6.5 & 8.5 & 5.1 & 5.3 & 9.2 & 4.2 \\
\hline March & 9.0 & 10.2 & 7.6 & 8.5 & 10.4 & 7.3 & 8.9 & 9.7 & 7.5 & 7.6 & 9.4 & 7.0 \\
\hline April & 13.1 & 15.5 & 12.9 & 11.4 & 11.4 & 11.8 & 9.4 & 16.5 & 12.3 & 10.9 & 15.1 & 12.1 \\
\hline May & 20.4 & 17.4 & 18.1 & 18.2 & 17.9 & 16.8 & 17.7 & 18.1 & 16.9 & 18.7 & 17.0 & 17.3 \\
\hline June & 22.5 & 23.9 & 22.4 & 21.3 & 23.6 & 21.3 & 21.5 & 22.9 & 21.1 & 21.0 & 23.3 & 21.6 \\
\hline Means & 12.7 & 13.8 & 11.6 & 12.9 & 13.9 & 12.1 & 11.9 & 14.6 & 11.7 & 11.4 & 13.3 & 11.2 \\
\hline
\end{tabular}

A: 2014-2015 growing season, B: 2015-2016 growing season, C: Long-term average

*Kirklareli central station data 
Table 3. Results of combined variance analysis for grain yield

\begin{tabular}{c|c|c|c|c}
\hline Source of variation & $\begin{array}{c}\text { Degrees of freedom } \\
(\mathbf{D F})\end{array}$ & $\begin{array}{c}\text { Sum of squares } \\
(\mathbf{S S})\end{array}$ & $\begin{array}{c}\text { Mean square } \\
(\mathbf{M S})\end{array}$ & F \\
\hline Replication & 21 & 17.482 & $0.832^{* *}$ & 2.36 \\
Environment & 6 & 155.852 & $25975^{* *}$ & 73.74 \\
Genotype & 16 & 133.270 & $8329^{* *}$ & 23.65 \\
Genotype $\times$ Environment & 96 & 85.926 & $0.895^{* *}$ & 2.54 \\
Error & 336 & 118.361 & 0.352 & \\
Corrected total & 475 & 510.891 & & \\
\hline CV $(\%): 8.96$ & & & & \\
\hline
\end{tabular}

$* *$ Significant at 0.01 probability level

Table 4. Mean yield of 17 bread wheat genotypes tested across 7 environments $\left(t h a^{-1}\right)$

\begin{tabular}{c|c|c|c|c|c|c|c|c}
\hline \multirow{2}{*}{ Genotypes } & \multicolumn{7}{|c|}{ Environments $^{3}$} & \multirow{2}{*}{ Mean $^{2}$} \\
\cline { 2 - 7 } & $\mathbf{E 1}$ & $\mathbf{E 2}$ & $\mathbf{E 3}$ & $\mathbf{E 4}$ & $\mathbf{E 5}$ & $\mathbf{E 6}$ & $\mathbf{E} 7$ & \\
\hline Gelibolu $^{1}$ & 7.875 & 6.568 & 6.926 & 5.280 & 5.840 & 6.572 & 6.900 & $6.566 \mathrm{c-f}$ \\
Kate A-1 $^{1}$ & 7.430 & 5.256 & 5.852 & 4.514 & 5.971 & 5.765 & 5.927 & $5.816 \mathrm{~g}$ \\
Selimiye $^{1}$ & 6.924 & 4.342 & 5.569 & 4.047 & 6.246 & 5.916 & 5.993 & $5.577 \mathrm{~g}$ \\
Pehlivan $^{1}$ & 6.542 & 5.204 & 5.659 & 3.887 & 6.081 & 5.886 & 6.414 & $5.667 \mathrm{~g}$ \\
Krasunia odes'ka $^{1}$ & 7.765 & 6.812 & 6.524 & 6.372 & 6.191 & 6.772 & 7.357 & $6.827 \mathrm{bc}$ \\
Energo $^{\text {Yigit }}$ & 7.224 & 6.602 & 6.705 & 4.767 & 6.928 & 5.615 & 6.397 & $6.320 \mathrm{f}$ \\
Maya & 7.827 & 6.093 & 6.932 & 5.468 & 5.793 & 6.302 & 6.985 & $6.486 \mathrm{def}$ \\
Asli & 7.936 & 6.641 & 6.422 & 5.792 & 5.728 & 6.510 & 7.393 & $6.632 \mathrm{cde}$ \\
Huseyinbey & 7.410 & 7.526 & 7.463 & 5.220 & 7.861 & 6.954 & 7.718 & $7.164 \mathrm{a}$ \\
Dunaviya & 7.301 & 7.887 & 7.819 & 5.999 & 6.904 & 7.028 & 7.304 & $7.177 \mathrm{a}$ \\
Pannonia & 7.450 & 6.690 & 6.582 & 6.176 & 6.788 & 6.236 & 6.420 & $6.620 \mathrm{c}-\mathrm{f}$ \\
Misiia Odes'ka & 8.076 & 7.095 & 6.253 & 5.555 & 6.017 & 6.806 & 7.357 & $6.737 \mathrm{cde}$ \\
Rebelde & 7.565 & 7.517 & 6.990 & 6.012 & 6.961 & 7.438 & 7.371 & $7.122 \mathrm{ab}$ \\
Nomade & 7.749 & 7.817 & 7.025 & 5.901 & 7.794 & 7.342 & 7.667 & $7.328 \mathrm{a}$ \\
Os Jelena & 7.285 & 7.784 & 6.296 & 6.937 & 7.189 & 7.850 & 8.082 & $7.346 \mathrm{a}$ \\
Duru 17 & 7.304 & 6.215 & 6.593 & 5.579 & 5.856 & 7.070 & 6.441 & $6.437 \mathrm{ef}$ \\
\hline Mean & 7.957 & 6.504 & 6.869 & 5.227 & 6.701 & 7.202 & 7.081 & $6.791 \mathrm{~cd}$ \\
\hline
\end{tabular}

${ }^{1}$ Control cultivars

${ }^{2}$ Least Significant Difference (LSD) of genotypes: 0.312 (for alpha 0.05)

${ }^{3}$ Codes of environments are given in Table 1

For the assessment of multi-environment trials, initially mega-environments were determined to explain which-won-where model. Polygon view of GGE-biplot is an efficient means of data assessment (Yan and Kang, 2003; Yan, 2014). A polygon view is generated through connecting genotype pointers furthest located from the biplot origin and called as a vertex (Fig. 3). Eight orthogonal rays were drawn from the biplot origin to polygon sides or side extensions. In this way, 8 sectors were generated including environments and genotypes. Vertex genotypes are considered as the best genotype of that sector and the genotypes between the vertex genotype and the biplot 
origin were considered as less sensitive. Despite 8 sectors were generated with the rays drawn, there were 3 mega-environments (ME) in the biplot graph. E1 (Kesan-2015) constituted ME-1; E2 (Kesan-2016), E3 (Edirne-2015), E4 (Edirne-2016), E6 (Tekirdag-2016) and E7 (Luleburgaz-2016) constituted ME-2 and E5 (Tekirdag-2015) constituted ME-3. G12 (Pannonia) and G8 (Maya) were identified as vertex genotypes of ME-1, G15 (Nomade) was the vertex genotype of ME-2 and G9 (Asli) was identified as the vertex genotype of ME-3.

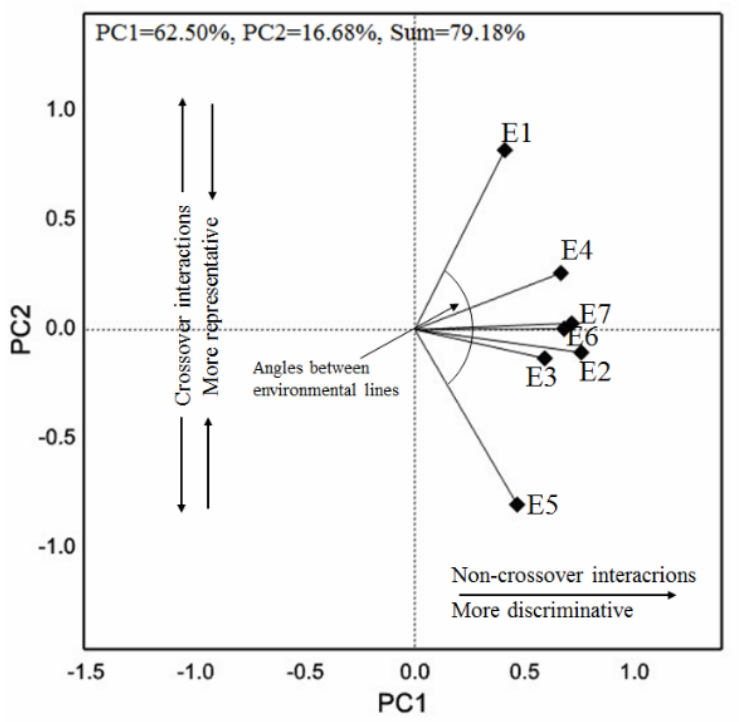

Figure 2. The vector view of the GGE biplot among the trial environments. Abbreviations of environments are given in Table 1

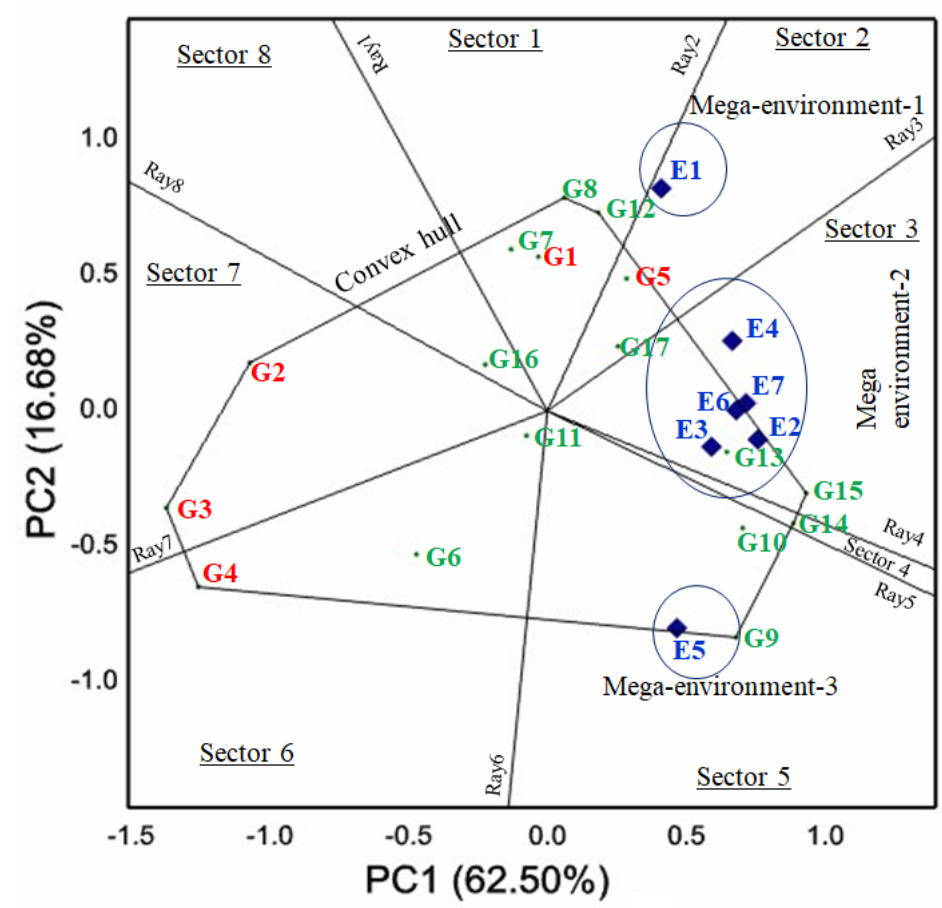

Figure 3. The polygon view of the GGE biplot based on pattern for 17 bread wheat genotypes and trial environments. Codes of environments and genotypes are given in Table 1 
In Figure 4, the average environment coordinate (AEC) connecting average environment point representing the entire environments to biplot origin was drawn. In this way, the apsis of AEC was formed. The ordinate of AEC passes through the biplot origin and is orthogonal to AEC apsis (Yan and Kang, 2003). The arrow on AEC apsis shows the direction from the lower genotype effect to the higher genotype effect. AEC ordinate expresses bi-directional effect and indicates decreasing stability as moved away from the AEC apsis (Yan, 2001; Yan, 2002). From the ordinate of AEC to high performance along the AEC apsis, genotypes were respectively ordered as G8, G12, G17, G5, G13, G9, G10, G14 and G15. The other genotypes were left below the average. Considering the distances of genotypes (vector lengths) between AEC ordinate and average from the AEC apsis, it was observed that G13 was the closest cultivar to AEC apsis. The genotypes of G15, G14, G10 and G13 with high PC1 values and relatively shorter vector lengths to AEC apsis were expressed as stable genotypes. Although G9, G12 and G8 were above the average, they placed furthest to AEC apsis. In other words, although these cultivars were above the average, they were not able to exhibit stable performance in changing environments, thus they were considered as less stable cultivars. G11 was the closest cultivar to biplot origin, thus exhibited the least reaction to changing environments.

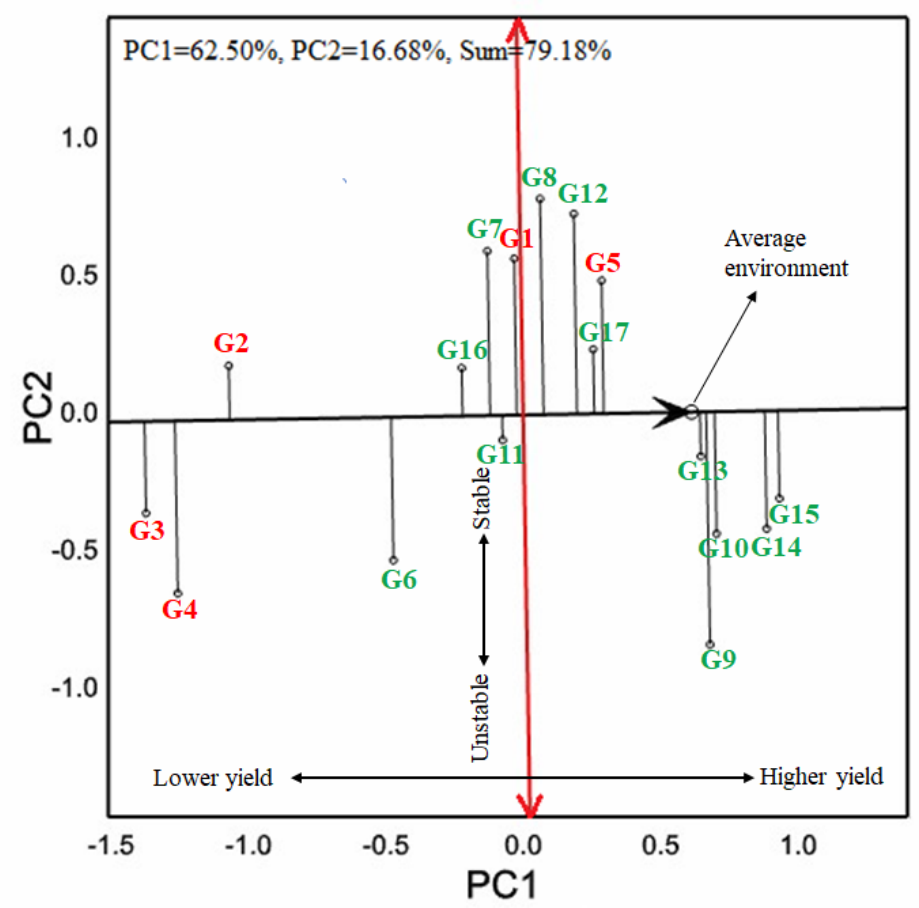

Figure 4. The view of the distribution according to AEC of 17 bread wheat genotypes. Codes of genotypes are given in Table 1

From a different perspective, assessments were made based on the ideal genotype in Figure 5a. The innermost circle represents the ideal genotype and the other circles represent the distance of other genotypes to the ideal genotype circle. G15 placed on the border of the innermost circle. G14, G10 and G13 were close to the ideal genotype region. Gradually increasing circle diameters indicate the way to undesirable genotypes region. 
As it was in ideal genotype-focused assessments in Figure $5 a$, the environmentfocused assessments are presented in Figure 5b. The environment E7 (Luleburgaz2016) placed closest to the ideal environment center. Thus, E7 was considered as the best representative of all environments and thus had the greatest power of separation for genotypes. E1 and E5 were placed furthest from the ideal environment circle. These two environments constituted separately the ME-1 and ME-3 as presented in Figure 3.

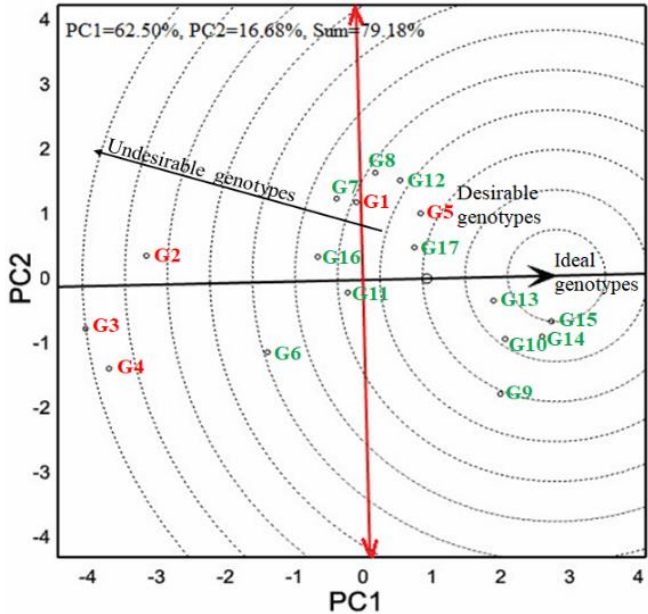

(a)

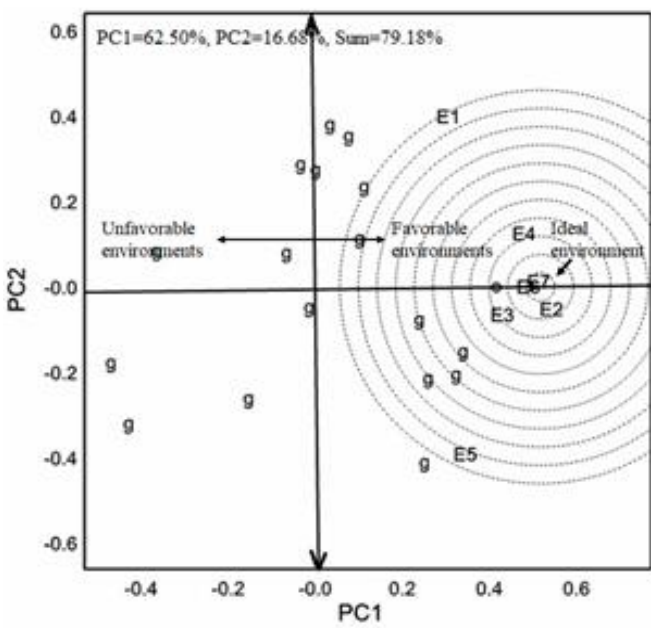

(b)

Figure 5. (a) Comparison of 17 bread wheat genotypes with the ideal genotype. (b) Comparison of test environments with the ideal environment. Codes of environments and genotypes are given in Table 1

\section{Quality traits}

The 1000-kernel weights, test weights, protein contents, Zeleny sedimentation and alveograph energy values of 17 bread wheat genotypes tested at 7 different environments are provided in Table 5. The variance analysis revealed significant differences $(p \leq 0.01)$ in the quality traits between genotypes. The biplot graphs were generated separately for each quality trait. In VCU trials, candidate varieties are compared with the control varieties in terms of performance and adaptability. For quality criteria, the average of control cultivars (AC) was generated over the average of G1, G2, G3, G4 and G5 accepted as the control cultivars in each environment and candidate varieties were assessed on biplot over AC values.

\section{Thousand-kernel weight}

Regarding 1000-kernel weight, the genotypes G7, G10, G13, G11, G5, G1, G3, G6 and G4 gave PC1 values above the AEC ordinate (Fig. 6a). Among them, G4 had the greatest average 1000-kernel weight with the greatest vector length to AEC apsis. G7 and G8 were quite close to biplot origin, thus they were considered as the least sensitive to the environment. Of the genotypes with positive PC1 scores, except for G4 and G10, the others had close vector lengths to AEC. When the 1000-kernel weights were assessed over AC values, it was observed that G6 was the only genotype with a value greater than AC (Fig. 6b). Except for G6, all the other genotypes had values lower than AC. G14 had the lowest 1000-kernel weight, thus placed furthest to AEC and 
considered as the least stable variety (Fig. 6a). The 1000-kernel weight is a significant yield parameter and greatly influenced by the genotype and environment (Mut et al., 2005). Besides being a yield component, it also reveals significant information about the flour yield (Aydogan and Soylu, 2017). With the GGE-biplot analysis on 1000kernel weights, $79.75 \%$ of GGE-induced variation was explained.

Table 5. Mean and standard deviation of some quality characteristics of 17 bread wheat genotypes tested across 7 environments ${ }^{l}$

\begin{tabular}{c|c|c|c|c|c}
\hline Genotypes & $\begin{array}{c}\text { 1000 Kernel } \\
\text { weight }(\mathbf{g})\end{array}$ & $\begin{array}{c}\text { Test weight } \\
(\mathbf{k g})\end{array}$ & $\begin{array}{c}\text { Protein } \\
\text { content (\%) }\end{array}$ & $\begin{array}{c}\text { Zeleny } \\
\text { sedimentation (ml) }\end{array}$ & $\begin{array}{c}\text { Alveograph energy } \\
\text { value (10 } \mathbf{~ J o u l e )}\end{array}$ \\
\hline Gelibolu $^{2}$ & $35.5(2.7)$ & $79.1(1.5)$ & $12.6(0.8)$ & $45.1(13.0)$ & $253.1(43.2)$ \\
Kate A-1 $^{2}$ & $33.4(3.1)$ & $78.3(1.7)$ & $13.8(1.1)$ & $40.3(16.5)$ & $178.6(27.0)$ \\
Selimiye $^{2}$ & $35.7(1.8)$ & $79.5(1.6)$ & $13.2(1.1)$ & $45.4(17.5)$ & $206.9(45.0)$ \\
Pehlivan $^{2}$ & $39.8(4.1)$ & $79.2(1.4)$ & $12.8(0.7)$ & $35.4(14.9)$ & $164.9(42.1)$ \\
Krasunia odes'ka $^{2}$ & $35.4(2.2)$ & $78.1(1.3)$ & $13.1(0.5)$ & $57.4(12.1)$ & $254.6(44.9)$ \\
Energo & $36.4(2.5)$ & $79.4(1.1)$ & $15.5(1.1)$ & $55.1(11.5)$ & $282.6(71.6)$ \\
Yigit & $34.4(3.4)$ & $76.8(1.6)$ & $13.6(1.0)$ & $39.1(8.9)$ & $199.6(47.2)$ \\
Maya & $34.1(2.1)$ & $76.9(1.7)$ & $12.1(0.7)$ & $38.9(9.3)$ & $169.0(34.0)$ \\
Asli & $33.8(3.7)$ & $78.8(2.0)$ & $13.6(0.6)$ & $52.6(12.3)$ & $266.7(34.8)$ \\
Huseyinbey & $35.3(3.6)$ & $76.7(1.9)$ & $12.7(0.7)$ & $43.3(12.6)$ & $186.6(26.8)$ \\
Dunaviya & $35.4(2.3)$ & $78.3(1.0)$ & $13.1(0.7)$ & $54.3(12.9)$ & $229.7(39.8)$ \\
Pannonia & $33.8(3.9)$ & $78.3(2.2)$ & $13.5(1.1)$ & $49.1(17.4)$ & $245.1(59.2)$ \\
Misiia Odes'ka & $35.3(3.6)$ & $77.7(1.7)$ & $12.4(0.9)$ & $48.1(13.6)$ & $221.0(37.6)$ \\
Rebelde & $28.3(5.1)$ & $79.0(1.7)$ & $14.9(0.6)$ & $63.7(9.9)$ & $267.4(81.3)$ \\
Nomade & $32.6(2.6)$ & $76.0(1.6)$ & $13.4(0.8)$ & $49.7(13.8)$ & $180.0(50.0)$ \\
Os Jelena & $31.3(1.7)$ & $80.2(1.9)$ & $13.3(0.6)$ & $52.3(12.8)$ & $249.7(42.0)$ \\
Duru 17 & $32.1(2.7)$ & $77.2(1.6)$ & $13.9(0.6)$ & $48.3(11.9)$ & $253.9(74.2)$ \\
\hline Mean & 34.27 & 78.21 & 13.37 & 48.13 & 224.08 \\
\hline LSD & $2.21 * *$ & $1.02 * *$ & $0.69^{* *}$ & $5.95^{* *}$ & $43.87 * *$ \\
\hline
\end{tabular}

${ }^{1}$ The values in brackets indicate the standard deviation

${ }^{2}$ Control cultivars

**Significant at 0.01 probability level

\section{Test weight}

The genotypes of G2, G12, G11, G9, G14, G1, G4, G6, G3 and G16 had high PC1 values greater than the average on the test weight's biplot graph (Fig. $7 a$ ). Since G4 was placed over the AEC apsis indicates it was considered as the most stable genotype. Although G16, G3 and G6 had greater PC1 scores, they had the longest vector lengths to AEC apsis. The G15 with the greatest PC1 score for grain yield had the least PC1 score and a PC2 score of 0.0 for test weight. Besides having the least test weight, G15 proved such a trait in all environments. With regard to control cultivar-focused GGEbiplot, the AC axis had a greater PC1 score than the AEC axis (Fig. 7b). Such a case indicated that average of control cultivar was greater than the average of environments. Test weight is a physical analysis like 1000-kernel weight and reveals information about the shape, size and density of kernels (Bulut, 2012; Aktas et al., 2017). 


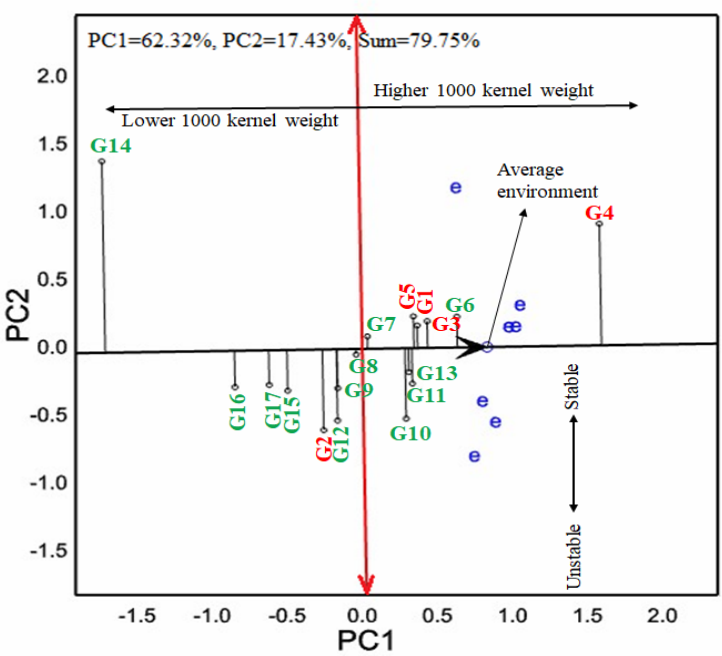

(a)

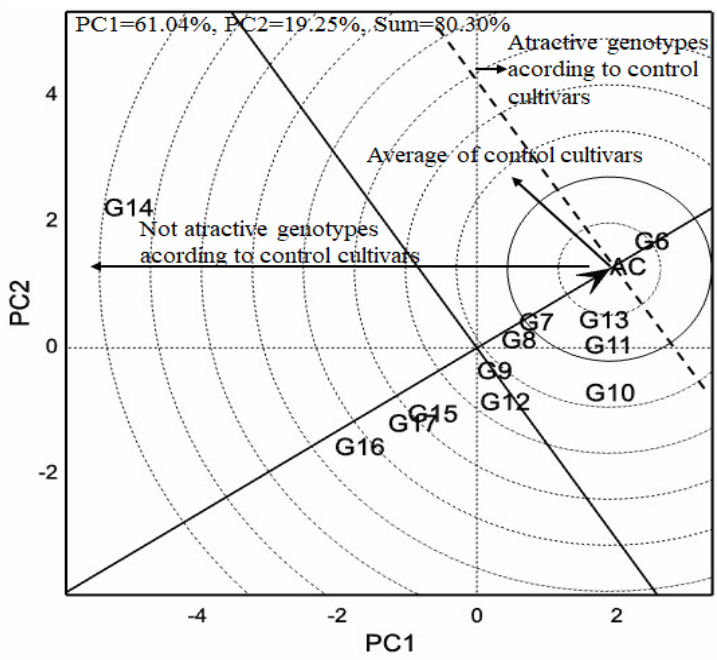

(b)

Figure 6. (a) The view of the distribution of 1000 kernel weight of 17 bread wheat genotypes according to AEC. (b) Comparison of 12 bread wheat genotypes in terms of 1000 kernel weight with the average of control cultivars $(A C)$. Codes of genotypes are given in Table 1

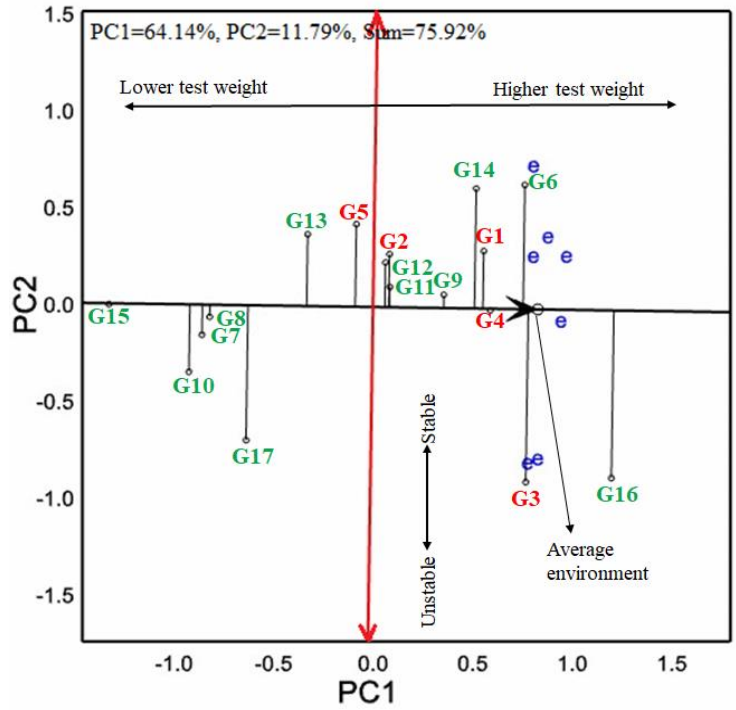

(a)

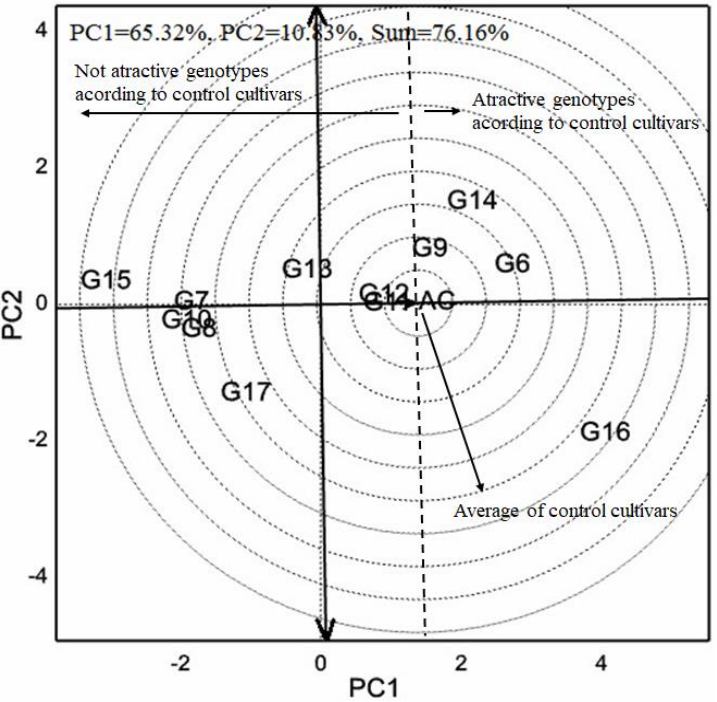

(b)

Figure 7. (a) The view of the distribution of test weight of 17 bread wheat genotypes according to AEC. (b) Comparison of 12 bread wheat genotypes in terms of test weight with the average of control cultivars $(A C)$. Codes of genotypes are given in Table 1

\section{Protein content}

When evaluating genotypes from the aspect of protein content, G7, G12, G9, G2, G17, G14 and G6 had high PC1 scores over the averages (Fig. 8a). Since G9 was placed on AEC apsis, it was considered as the most stable genotype. The G6 was the most prominent genotype since it had the greatest PC1 score and was placed as the second closest genotype to the AEC axis after G9. The G14 had the second greatest PC1 score after G6, but it had a high vector length to AEC. In Figure 8b, biplot graphs were 
generated through reversing PC1 and PC2 axes. When the assessments were done through comparisons with the control cultivars, it was observed that G10, G13 and G8 were placed behind the AC axis, in other words, they had lower protein contents than the control cultivars. The other genotypes had protein contents of above AC. Protein content is a significant quality trait for bread wheat and greatly influenced by the genotype and environment (Kahraman et al., 2017). Keceli et al. (2017) reported significant positive correlations between protein content and the other significant quality attributes.

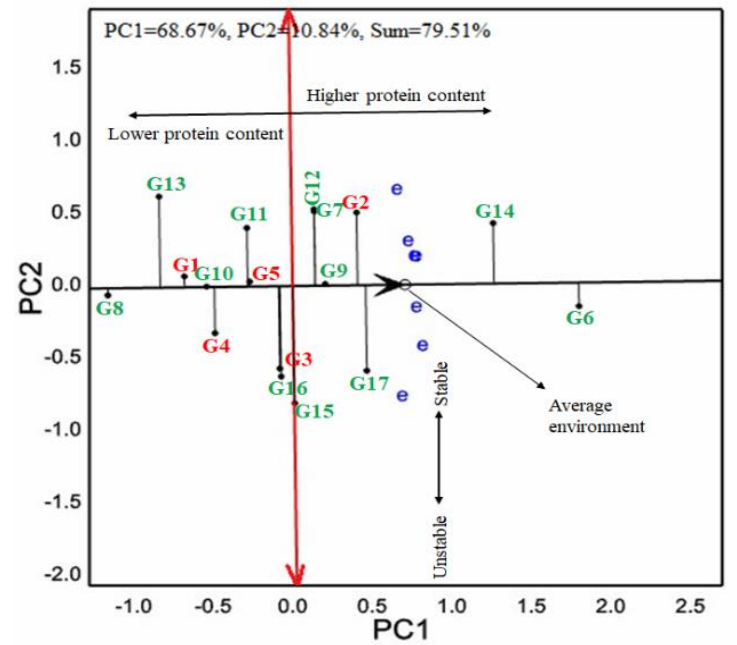

(a)

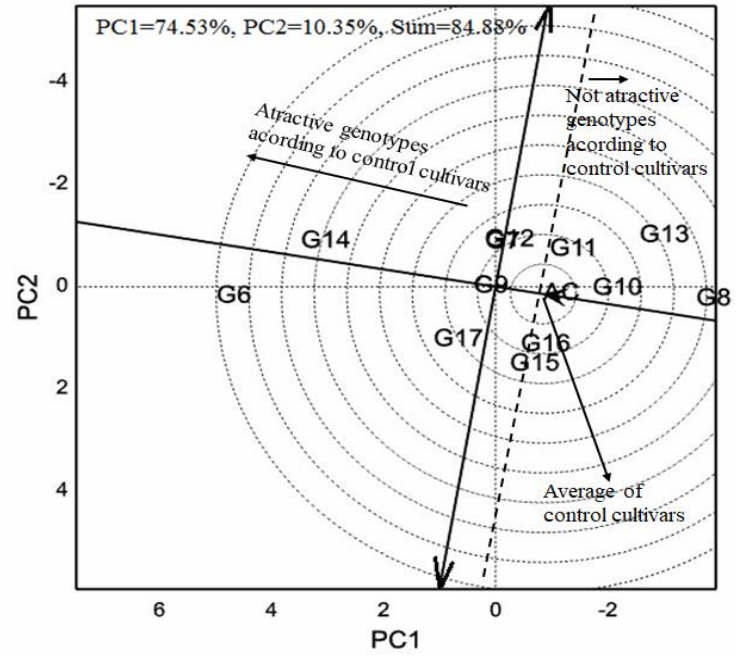

(b)

Figure 8. (a) The view of the distribution of protein content of 17 bread wheat genotypes according to AEC. (b) Comparison of 12 bread wheat genotypes in terms of protein content with the average of control cultivars $(A C)$. Codes of genotypes are given in Table 1

\section{Zeleny sedimentation and alveograph energy value}

With regard to Zeleny sedimentation, G13, G15, G12, G16, G9, G11, G6, G5 and G14 were placed over the average (Fig. 9a). G13, G9, G11, G6 and G5 were the closest genotypes to the AEC axis. G14 had the greatest sedimentation score and a high vector length to AEC. G7, G8, G1, G2 and G3 with negative PC1 scores were placed furthest to AEC. These genotypes were behind the average of environments and quite sensitive to the environment. The G17 on biplot origin was considered as the least sensitive genotype to changing environments. When the Zeleny sedimentation values of the genotypes were compared with the values of control cultivars, it was observed that the majority of them had scores of above the AC (Fig. 9b). In Figure 9b, PC1 and PC2 axes were reversed. G10, G7 and G8 had scores of below AC. Zeleny sedimentation is considered as an indicator of protein quality and high values are desired in bread wheat (Sahin et al., 2017; Aydogan and Soylu, 2017).

Alveograph energy values yield significant information about the bread-making quality of the flour (Aydogan et al., 2012). The genotypes of G11, G16, G17, G12, G1, G5, G14, G9 and G6 had greater values than the average and thus had high PC1 scores, but their vector lengths to AEC were quite different (Fig. 10a). G6 had the greatest alveograph energy value. G14 had the greatest vector length to the AEC axis. As it was 
in protein content, the majority of the varieties had values over the $\mathrm{AC}$ axis (Fig. 10b). G7, G8, G10 and G15 had lower values than the control cultivars. The other genotypes were above the AC.

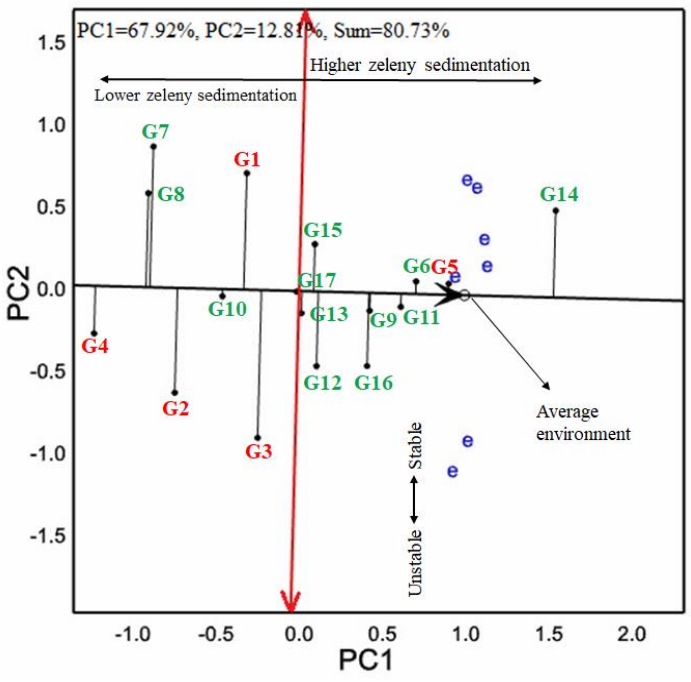

(a)

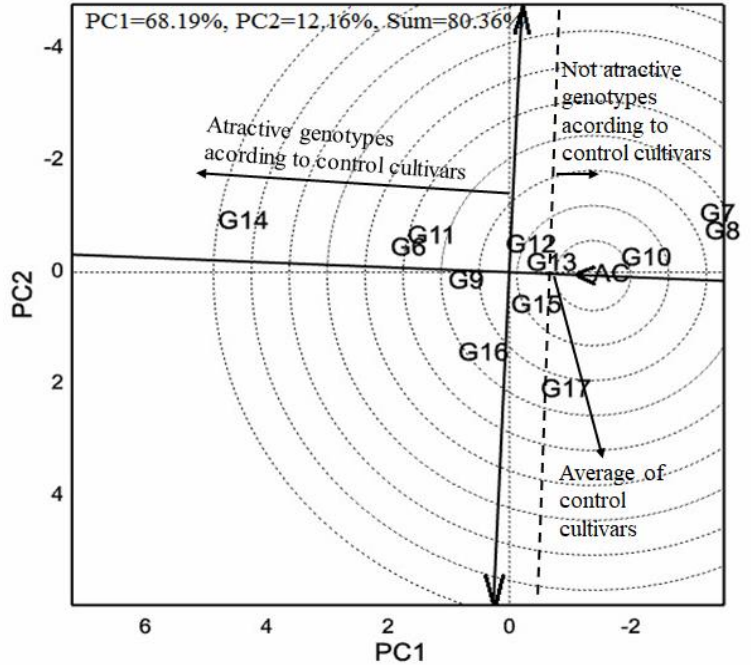

(b)

Figure 9. (a) The view of the distribution of Zeleny sedimentation of 17 bread wheat genotypes according to AEC. (b) Comparison of 12 bread wheat genotypes in terms of Zeleny sedimentation with the AC. Codes of genotypes are given in Table 1

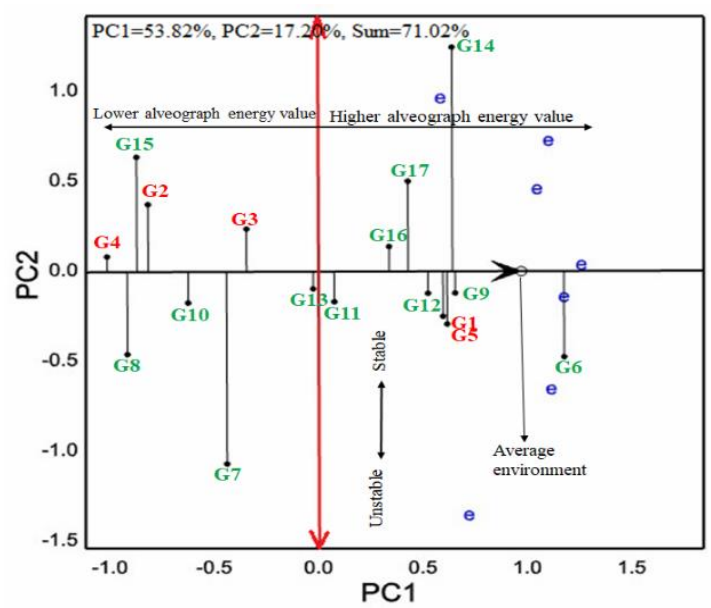

(a)

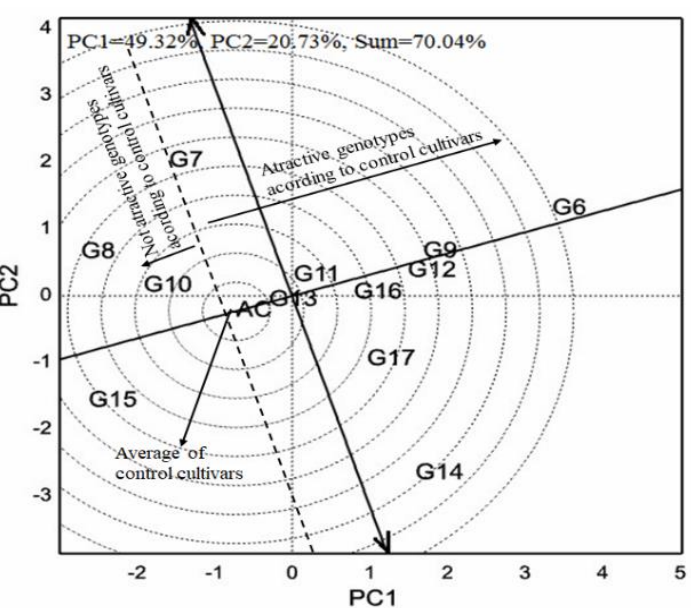

(b)

Figure 10. (a) The view of the distribution of alveograph energy value of 17 bread wheat genotypes according to AEC. (b) Comparison of 12 bread wheat genotypes in terms of alveograph energy value with the AC. Codes of genotypes are given in Table 1

\section{Conclusion}

A general assessment on grain yields revealed that control cultivars (Gelibolu, Kate A-1, Selimiye, Pehlivan, Krasunia odes'ka) had lower values than the average and the other genotypes had close to or greater values than the average. With regard to physical 
quality traits (1000-kernel weight and test weight), control cultivars had greater values and genotypes exhibited different performances for the other quality traits. In this study, genotypes with quite high performance for both yield and quality traits were identified. Genotype responses to different environments and their stabilities in different environments were put forth.

The majority of Turkish agricultural lands are used in wheat culture. In recent years, several varieties were brought to Turkey from different countries and they were subjected to VCU trials. Although VCU trials are conducted for wheat based on regional adaptation capacities, climate parameters exhibited great variations from the long-term averages in recent years with the impacts of global warming. Wheat culture is practiced commonly under rain-fed conditions in Turkey, thus changes in environmental conditions play a significant role in the production. Genotype responses to changing environmental conditions with regard to yield, quality, diseases and other agricultural traits should be identified and registration reports should be prepared accordingly. Thrace region of Turkey is among the regions with the greatest number of varieties coming from abroad. Thus, the present study was conducted with 17 bread wheat varieties at 7 different environments of the Thrace region. Present findings revealed that GGE-biplot analysis could reliably be used in VCU trials for yield and quality traits. Grouping of experimental environments based on genotype responses, put forth of which-won-where model visually on graph and comparisons of environments and genotypes yielded quite significant assessments for the VCU trial reports.

Performance of registration experiments for new cultivars developed through longterm breeding programs is a significant issue for both breeders and growers. Grain yield is the most significant criterion for bread wheat in Turkey. Despite the satisfactory levels in grain yields, quality then became a dominant criterion in recent years. High stability in quality attributes besides high stability in grain yields will have great contributions to widespread of new cultivars.

\section{REFERENCES}

[1] AACC (2000): American Association of Cereal Chemists, Approved Methods of the AACC. $10^{\text {th }}$ Ed. Method No: 54-50. - The Association, St. Paul, MN.

[2] Akcura, M., Akan, K., Hocaoglu, O. (2017): Biplot analysis of leaf rust resistance in pure lines selected from eastern Anatolian bread wheat landraces of Turkey. - Turkish Journal Field Crops 22(2): 227-234.

[3] Aktas, H., Erdemci, I., Karaman, M., Kendal, E., Tekdal, S. (2017): Evaluation grain yield and some quality traits of winter bread wheat genotypes using GGE-biplot analysis. - Tr. J. Nature Sci. 6(1): 43-51.

[4] Aydogan, S., Akcacik, A. G., Sahin, M., Kaya, Y., Koc, H., Gorgulu, M. N., Ekici, M. (2012): Determination of the relations between rheological properties of wheat flour which measured with alveograph, farinograph and mixograph. - Suleyman Demirel Un. Faculty of Agriculture Journal 7(1): 74-82.

[5] Aydogan, S., Soylu, S. (2017): Determination of yield, yield components and some quality properties of bread wheat varieties. - Journal of Field Crops Central Research Institute 26(1): 24-30.

[6] Bulut, S. (2012): Quality in bread wheat. - Journal of Erciyes University Institute of Natural and Applied Science 28(5): 441-446. 
[7] Farias, F. J. C., Carvalho, L. P., Silva Filho, J. L., Teodoro, P. E. (2016): Biplot analysis of phenotypic stability in upland cotton genotypes in Mato Grosso. - Genetics and Molecular Research 15(2): gmr.15028009.

[8] Flis, B., Domanski, L., Zimnoch-Guzowska, E., Polgar, Z., Pousa, S. A., Pawlak, A. (2014): Stability analysis of agronomic traits in potato cultivars of different origin. - Am. J. Potato Res. 91: 404-413.

[9] Gabriel, K. R. (1971): The biplot graphic display of matrices with application to principal component analysis. - Biometrika 58: 453467.

[10] Gebru, H., Hailemariam, A., Belay, T. (2011): Genotype by environment interaction and grain yield stability of early maturing bread wheat (Triticum aestivum L.) genotypes in the drought prone areas of Tigray region, northern Ethiopia. - Ethiopian Journal of Science and Technology 2(1): 51-57.

[11] GenStat (2009): GenStat for Windows (12 ${ }^{\text {th }}$ Ed.) Introduction. - VSN International, Hemel Hempstead.

[12] ICC (2002a): Determination of Crude Protein in Cereals and Cereal Products for Food and Feed. Standard No: 105/2. - International Association for Cereal Science and Technology (ICC), Vienna.

[13] ICC (2002b): Standard Methods of International Association for Cereal Science and Technology. - ICC-Vienna.

[14] Kahraman, T., Ozturk, I., Avci, R., Aktas, H. (2017): The Effects of Genotype x environment interaction on some quality assessments in bread wheat (T. aestivum L.). Journal of Central Research Institute for Field Crops 26(Special Issue): 15-22.

[15] Kaya, Y., Akcura, M., Taner, S. (2006): GGE-Biplot analysis of multi-environment yield trials in bread wheat. - Turkish Journal of Agriculture \& Forestry 30: 325-337.

[16] Keceli, A., Evlice, A. K., Pehlivan, A., Sanal, T., Karaca, K., Kulen, S., Subasi, A. S., Salantur, A. (2017): Investigation of the relationship between Zeleny sedimentation analysis and other quality parameters in bread wheat (Triticum aestivum L.). - KSU J. Nat. Sci. 20(Special Issue): 292-296.

[17] Mut, Z., Aydın, N., Ozcan, H., Bayramoglu, H. O. (2005): Determination of yield and some quality traits of bread wheat (Triticum aestivum L.) genotypes in the Middle Black Sea Region. - GOU Journal of Faculty of Agriculture 22(2): 85-93.

[18] Oyekunle, M., Haruna, A., Badu-Apraku, B., Usman, I. S., Mani, H., Ado, S. G., Olaoye, G., Obeng-Antwi, K., Abdulmalik, R. O., Ahmed, H. O. (2017): Assessment of earlymaturing maize hybrids and testing sites using GGE biplot analysis. - Crop Sci. 57: 29422950.

[19] RTMAF (2008): Regulation on Registration of Plant Varieties. - Republic of Turkey Ministry of Agriculture and Forestry, Official Newspaper, Date 13.01.2008, No: 26755.

[20] Sahin, M., Akcacik, A. G., Aydogan, S., Hamzaoglu, S., Demir, B., Yakisir, E. (2017): Investigation of the relationship between zeleny sedimentation and yield and some quality traits in winter bread wheat varieties. - J. of Bahri Dagdas Crop Research 6(1): $10-21$.

[21] Solonechnyi, P., Vasko, N., Naumov, A., Solonechnaya, O., Vazhenina, O., Bondareva, O., Logvinenko, Y. (2015): GGE biplot analysis of genotype by environment interaction of spring barley varieties. - Zemdirbyste-Agriculture 102(4): 431-436.

[22] TSMS (2018): Rainfall Assessment Report. - The Turkish State Meteorological Service, Ankara.

[23] Tulu, L., Wondimu, A. (2019): Adaptability and yield stability of bread wheat (Triticum aestivum) varieties studied using GGE-biplot analysis in the highland environments of South-western Ethiopia. - African Journal of Plant Science 13(6): 153-162.

[24] Uluoz, M. (1965): Wheat, Flour and Bread Analysis Methods. - Ege University Faculty of Agriculture Publications, Izmir, Publication number: 57. 
[25] Xu, N., Fok, M., Li, J., Yang, X., Yan, W. (2017): Optimization of cotton variety registration criteria aided with a genotype-by-trait biplot analysis. - Scientific Reports 7(1): 17237.

[26] Yan, W. (2001): GGE-biplot - a Windows application for graphical analysis of multienvironment trial data and other types of two way data. - Agron. J. 93: 1111-1118.

[27] Yan, W. (2002): Singular-value partitioning in biplot analysis of multienvironment trial data. - Agron. J. 94: 990-996.

[28] Yan, W. (2014): Crop Variety Trials: Data Management and Analysis. - WileyBlackwell, Hoboken, NJ.

[29] Yan, W., Hunt, L. A., Sheng, Q., Szlavnics, Z. (2000): Cultivar evaluation and megaenvironment investigation based on the GGE biplot. - Crop Sci. 40: 597-605.

[30] Yan, W., Kang, M. S. (2003): GGE-Biplot Analysis: A Graphical Tool for Breeders, Geneticists and Agronomists. - CRD Press, Boca Raton. 